\title{
Reproductive Health and Service Delivery Status in a Rural Area of Bangladesh
}

\author{
FAHMIDARASHID ${ }^{1}$, SHIREEN BEGUM ${ }^{2}$, M ASATTAR $^{3}$, SHAHANAJ SHARMIN $^{4}$, \\ KAMRUN NESA BEGUM ${ }^{5}$
}

\begin{abstract}
:
Background: Reproductive Healthcare Services is a service that contributes to reproductive health and wellbeing through preventing and solving reproductive health problems.

Objective of the Study: To find out the reproductive health status and also the service delivery pattern in a rural area.

Methodology: It is a cross sectional study done in a village named Kalirbazar, $3 \mathrm{~km}$ away from the BARD ,Comilla, during the period of $13^{\text {th }}$ February to $13^{\text {th }}$ March, 2011. Data were collected purposively by Individual interview through a structured questionnaire. A total 30 women of reproductive age group (15-45yrs) were taken. Both adolescent unmarried girls and married women of reproductive age group were included in this study. After collection, data were analyzed, tabulated and presented.

Results: Respondents were mostly married( 63\%) , unmarried 33\%; almost all of the women were Muslim (93\%) and from low socioeconomic status(77\%). Sixty six percent of women got married before $18 \mathrm{yrs}$ of age and $47 \%$ were illiterate, more than half of the women (60\%) were housewives and 28\% dropped out from schools. Forty percent of married women had 2-3 children.Most of the Women had knowledge about contraception, like-OCP (33\%), inj. (27\%), barrier (17\%), female sterilization (06\%) and 17\% had no knowledge. Among the married women 53\% use OCP, 32\% injectable contraceptives, $11 \%$ sterilization and $04 \%$ had vasectomy. Among respondents, $70 \%$ had some sorts of menstrual problem, $85 \%$ women lacked of antenatal checkup, 95\% delivery occurred at home, 90\% delivery conducted by local dhai and unexpectedly $73 \%$ of women had knowledge of STD/HIV\&AIDS. $60 \%$ of the women got the information related to reproductive health from relatives and also from media, health care provider. Most of the women (87\%) said that whatever the health service status; there were problems in getting the services. Only few of them were satisfied with the services getting either from $\mathrm{GO}$ or NGO or from private sector. Almost all the women were buying the reproductive healthcare services (83\%).
\end{abstract}

Conclusion: Reproductive health status in the rural area is not at all satisfactory. GO. and NGO often fail to make health services available to the doorstep of the users in the community who are in dire need of it .

Introduction:

Reproductive Healthcare Service is a service that contributes to reproductive health and well-being through preventing and solving reproductive health problems ${ }^{1}$. Reproductive health approach implies to those people who have the ability to reproduce and regulate their fertility; women who are able to go through pregnancy and child birth safely; the outcome of the pregnancy is successful in terms of maternal and infant survival and couples who are able to have sexual relations free of fear of pregnancy and contracting disease ${ }^{2}$.

1. Jr.Consultant(gynae \& Obs), UHC Hathazari,Chittagong.

2. Jr. Consultant (gynae \& Obs),Cox'SBazar Sadar Hospital.

3. Asst.Prof.(Medicine),Chittagong Medical College.

4. Asst. Prof.(Gynae \& Obs),BBMH,USTC,Chittagong.

5. Resident surgeon(Gynae \& Obs), $\mathrm{CMCH}$. 
Target groups for the reproductive healthcare services are women and men of different stages of life; adolescent ${ }^{3}$. Reproductive events in women's life can be divided in many parts such as: preconception, conception, childbirth, post-natal, interconnection, perimenopausal and infertility. In the ICPD (International Conference on Population and Development) in 1994 (held in Cairo) it was decided that the reproductive health services should be ensured to all ${ }^{4}$.

The above mentioned services should be provided with adequate care and quality but Bangladesh is largely lacking these services due to the absence of proper infrastructure and therefore the services are provided in a limited scale, current infrastructure which exists in Bangladesh does not fit to provide such services ${ }^{5}$. The existing service provides women's health services, family planning, safe delivery care, Essential Obstetric Care (EOC), referral services, and post-natal care. Prevention of unsafe abortion includes menstrual regulation (MR), prevention of unwanted pregnancy, and treatment of complications of abortion, postabortion counseling, information and counseling for clients requiring $\mathrm{MR}^{6}$.

In terms of physical facilities to provide reproductive healthcare services, an impressive number of facilities and staff are existing. The reproductive healthcare or the primary healthcare is provided in a three-tiered system: at district level, at Upazila level and at the Union level.

The study was conducted to find out the reproductive health status and also the service delivery pattern in a rural area.

\section{Methodology:}

The study was done in a village named Kalirbazar, 3 $\mathrm{Km}$ away from the BARD campus, Comilla, during the period of 13th February to $13^{\text {th }}$ March, 2011. . It was a cross sectional study and sample was taken purposively. Data were collected through individual interview and also with group discussion via a structured questionnaire. A total 30 women of reproductive age group (15-45yrs) were taken purposively .Both adolescent unmarried girls and married women of reproductive age group were included in this study. After collection of raw data, data were analyzed, tabulated. Presentation was done in the form of table, bar diagram and pie chart.
Results:

Table-I

Demographic characteristics of respondents:

\begin{tabular}{|c|c|}
\hline Variables & Percentage \\
\hline \multicolumn{2}{|l|}{ Age(Yrs) } \\
\hline $15-25$ & $47 \%(14)$ \\
\hline $26-35$ & $33 \%(10)$ \\
\hline $36-45$ & $20 \%(06)$ \\
\hline \multicolumn{2}{|l|}{ Socio economic Status } \\
\hline Low & $77 \%(23)$ \\
\hline Middle & $23 \%(07)$ \\
\hline High & $00 \%(00)$ \\
\hline \multicolumn{2}{|l|}{ Religion } \\
\hline Muslim & $93 \%$ \\
\hline Hindu & $07 \%$ \\
\hline \multicolumn{2}{|l|}{ Age at marriage(Yrs) } \\
\hline$<18$ & $65 \%(17)$ \\
\hline $19-29$ & $35 \%(07)$ \\
\hline \multicolumn{2}{|l|}{ Educational Status } \\
\hline Illiterate & $47 \%$ \\
\hline Primary & $30 \%$ \\
\hline Secondary & $23 \%$ \\
\hline \multicolumn{2}{|l|}{ Marital status } \\
\hline Married & $63 \%$ \\
\hline Unmarried & $33 \%$ \\
\hline Separated & $04 \%$ \\
\hline \multicolumn{2}{|l|}{ Occupation } \\
\hline Housewife & $60 \%(18)$ \\
\hline Drop out from schoo & $28 \%(08)$ \\
\hline Students & $06 \%(02)$ \\
\hline Day laborer & $06 \%(02)$ \\
\hline \multicolumn{2}{|l|}{ Para } \\
\hline 1 & $20 \%(04)$ \\
\hline $2-3$ & $40 \%(08)$ \\
\hline $4-5$ & $15 \%(03)$ \\
\hline$>5$ & $25 \%(05)$ \\
\hline
\end{tabular}

Table1. Reveals that $47 \%$ of the respondents belong to the age group $15-25 y$ rs, $77 \%$ of the women were from low socioeconomic status and only $23 \%$ from lower middle class, most of the women were muslim, $65 \%$ of women married at their early age $(<18 y r s)$ and only $35 \%$ married between 19-29yrs.

$47 \%$ of the women were illiterate and $30 \%$ had primary education, $63 \% \%$ of the respondents were married and $33 \%$ unmarried, $60 \%$ of women were housewife and $28 \%$ dropped out from school, $40 \%$ of women having $2-3$ child and $25 \%$ had $>5$ child. 
Table-II

Reproductive health status:

\begin{tabular}{lc}
\hline Variables & Percentage \\
\hline Contraceptive knowledge & \\
OCP & $70 \%$ \\
Injection & $45 \%$ \\
$17 \%$ & \\
Barrier & \\
Female Sterilization & $53 \%$ \\
Nil & $17 \%$ \\
Contraceptive practice & \\
OCP & $53 \%(10)$ \\
$\quad$ Injection & $32 \%(06)$ \\
Sterilization & $11 \%(02)$ \\
Vasectomy & $04 \%(01)$ \\
Source of information & \\
Percentage & $60 \%((18)$ \\
Relative & $20 \%(06)$ \\
$\quad$ Media & $10 \%(03)$ \\
Health care provider & $10 \%(03)$ \\
\hline
\end{tabular}

Table-III

Reproductive health problem \& service

\begin{tabular}{lc}
\hline Variables & Percentage \\
\hline Antenatal checkup & \\
$\quad$ Yes & $15 \%$ \\
$\quad$ Nil & $85 \%$ \\
Menstrual Problem & \\
$\quad$ Present & $30 \%$ \\
$\quad$ Absent & $70 \%$ \\
Place of delivery & \\
$\quad$ Home & $95 \%$ \\
$\quad$ Hospital & $05 \%$ \\
Conduction of delivery & \\
$\quad$ Local dhai & \\
$\quad$ Trained Person & $90 \%$ \\
Problem on Getting service & $10 \%$ \\
$\quad$ Yes & \\
$\quad$ No & $87 \%$ \\
Satisfection of women & $13 \%$ \\
$\quad$ Satisfied & \\
$\quad$ Not satisfied & $17 \%$ \\
Cost of service & $83 \%$ \\
$\quad$ Buying & \\
$\quad$ Free & $83 \%$ \\
Knowledge of STD & $17 \%$ \\
$\quad$ Present & \\
$\quad$ Absent & $73 \%$ \\
\hline
\end{tabular}

Table 2 shows that $70 \% \%$ of women had knowledge of OCP and also they had knowledge of injection, barrier, and sterilization. In spite of knowledge 53\% respondents practice ocp, 32\% injection and surprisingly $4 \%$ had vasectomy. Women get the information related to reproductive health from relatives and also from media, health care provider.

Table 3 shows that $70 \%$ of women do not have any menstrual problem and $85 \%$ of the women lacking any sort of antenatal checkup during their pregnancy period. Most of the delivery took place in home in unhygienic condition unless otherwise severely complicated and most of the delivery in the village was conducted by the local dhai.

\section{Limitation of the study}

The study was done in a very short span of time and sample size was small. The study was conducted only in a single village its observation is not sufficient to extrapolate the result to the population.

\section{Discussion:}

The study reveals that most of the women in this village married in their early adolescence and became mother soon. Most of them are illiterate and from lower socioeconomic status and

housewife. The adolescence was also from same socioeconomic status and most of them dropped out from school.

About the reproductive health status, women were not getting satisfactory level of service either from GO or from NGO, most of them getting reproductive health service from local pharmacy, LMF doctors. They could mention the name of local Govt. health centre and NGO-ASHA, BRAC; but they were not happy with the service.

Most of the women were aware of contraception and also practicing. They were also aware of STD, HIV\&AIDS, which they informed from relatives, media and health worker.

At the end it is clear that the reproductive health status in the rural area was completely neglected and govt. and NGO were failed to give access of health service in the doorstep of our country. 


\section{Conclusion \& Recommendations:}

1. Decentralization of the health facility in every corner of the country is necessary.

2. Primery health care facility should expand .

3. The activity of the community clinic's should revive and should be well equipped.

4. The current project of Govt. and NGO should emphasize on women health.

5. The hospital should be women friendly.

6. To give information and to increase awareness of people about reproductive health facility ,different media like TV,radio,newspaper should give more emphasis

7. For improving reproductive health status literacy rate and socio economic status should improve.

\section{References:}

1. ICPD Programme of Action,1994, paragraph 7.2.

2. Fathalla MF. 1988. Research needs in human reproduction In: Research in Human Reproduction: Biennial Report (1986-1987). Edited by E. Diczfalusy, P.D. Griffin \& J. Khanna. World Health Organization, Geneva. p.341.

3. World Health Organization, http://www.who.int.

4. ICPD Programme of Action, 1994, paragraph 7.3.

5. Summary findings 1994, 1995, 1996 \& 1999 Health \& Demographic Survey (HDS). BBS

6. The 1993-94, 1996-97, 1999-2000 Bangladesh Demographic \& Health Survey (BDHS).

7. uww.banglapedia.org/httpdocs/HT/R_0182.HTM. 